\title{
MiRNA-29b and miRNA-497 Modulate the Expression of Carboxypeptidase X Member 2, a Candidate Gene Associated with Left Ventricular Hypertrophy
}

\author{
Jana Subrova *D, Karen Böhme, Allan Gillespie ${ }^{D}$, Miriam Orphal, Claudia Plum, Reinhold Kreutz \\ and Andreas Eisenreich
}

check for

updates

Citation: Subrova, J.; Böhme, K.; Gillespie, A.; Orphal, M.; Plum, C.; Kreutz, R.; Eisenreich, A. MiRNA-29b and miRNA-497 Modulate the Expression of Carboxypeptidase $X$ Member 2, a Candidate Gene Associated with Left Ventricular Hypertrophy. Int. J. Mol. Sci. 2022, 23, 2263. https://doi.org/10.3390/ ijms23042263

Academic Editor: Gaetano Santulli

Received: 17 January 2022

Accepted: 14 February 2022

Published: 18 February 2022

Publisher's Note: MDPI stays neutral with regard to jurisdictional claims in published maps and institutional affiliations.

Copyright: (C) 2022 by the authors. Licensee MDPI, Basel, Switzerland. This article is an open access article distributed under the terms and conditions of the Creative Commons Attribution (CC BY) license (https:// creativecommons.org/licenses/by/ $4.0 /)$.
Institute of Clinical Pharmacology and Toxicology, Charité-Universitätsmedizin Berlin, Corporate Member of Freie Universität Berlin, Humboldt-Universität zu Berlin, and Berlin Institute of Health, 10117 Berlin, Germany; karen.boehme@charite.de (K.B.); allan.gillespie@charite.de (A.G.); miriam.orphal@charite.de (M.O.); claudia.plum@charite.de (C.P.); reinhold.kreutz@charite.de (R.K.); andreas.eisenreich@gmx.de (A.E.)

* Correspondence: jana.subrova@charite.de; Tel.: +49-30-450525112; Fax: +49-30-4507525112
Abstract: Left ventricular hypertrophy (LVH) is a major risk factor for adverse cardiovascular events. Recently, a novel candidate gene encoding the carboxypeptidase X member 2 (CPXM2) was found to be associated with hypertension-induced LVH. CPXM2 belongs to the M14 family of metallocarboxypeptidases, yet it lacks detectable enzyme activity, and its function remains unknown. Here, we investigated the impact of micro (mi)RNA-29b, miRNA-195, and miRNA-497 on the posttranscriptional expression control of CPXM2. Candidate miRNAs for CPXM2 expression control were identified in silico. CPXM2 expression in rat cardiomyocytes (H9C2) was characterized via real-time PCR, Western blotting, and immunofluorescence. Direct miRNA/target mRNA interaction was analysed by dual luciferase assay. CPXM2 was expressed in H9C2 and co-localised with z-disc associated protein PDZ and LIM domain 3 (Pdlim3). Transfection of H9C2 with miRNA-29b, miRNA195, and miRNA-497 led to decreased levels of CPXM2 mRNA and protein, respectively. Results of dual luciferase assays revealed that miRNA-29b and miRNA-497, but not miRNA-195, directly regulated CPXM2 expression on a posttranscriptional level via binding to the $3^{\prime} \mathrm{UTR}$ of CPXM2 mRNA. We identified two miRNAs capable of the direct posttranscriptional expression control of CPXM2 expression in rat cardiomyocytes. This novel data may help to shed more light on the-so far-widely unexplored expression control of CPXM2 and its potential role in LVH.

Keywords: carboxypeptidase $\mathrm{X}$ member 2; microRNA; posttranscriptional; gene expression; left ventricular hypertrophy

\section{Introduction}

Cardiovascular diseases (CVDs) remain the most prevalent cause of morbidity and mortality worldwide [1-3]. High blood pressure is one of the principal risk factors for the development of CVDs, such as heart failure, coronary heart disease, atrial fibrillation, and stroke [4]. Although intensive research on the field of pathogenesis in cardiovascular system has been performed for decades, molecular mechanisms leading to CVDs in humans are still not entirely understood [5]. Yet, the knowledge about the molecular pathways involved in the development and progression of CVDs is essential in the search for more efficient targeted therapies.

Carboxypeptidase (CP) X member 2 (CPXM2) is a member of the M14 family and the N/E subfamily of metallocarboxypeptidases [6]. However, it does not show any detectable enzymatic activity. Recently, the gene encoding CPXM2 was found to be associated with the development of hypertension-induced left ventricular hypertrophy (LVH) in mice [7]. CPXM2 overexpression was also reported to promote proliferation, migration 
and the epithelial to mesenchymal transition of osteosarcoma cells [8], as well as gastric cancer cells [9].

CPs represent a large group of enzymes involved in the C-terminal cleavage of different substrates, such as food proteins and neuropeptides [10]. The N/E subfamily contains three members which lack catalytic function. In addition to CPXM2, CP X member 1 (CPXM1) and aortic CP-like protein/adipocyte enhancer-binding protein 1 (ACLP/AEBP1) were found not to hydrolyse any of the tested CP substrates [6]. These findings are consistent with the fact that the CP domains of CPXM1, CPXM2, and AEBP1 lack different amino acid residues responsible for the catalytic function and/or substrate binding in active CPs [11].

CPXM2 was first discovered and described by Xin et al. in 1998. CPXM2 is expressed in various tissues, including brain, liver [6], inner ear [12] and heart [7]. Moreover, its sequence is evolutionarily conserved in different species, such as zebrafish, mice and humans (https: / / www.ncbi.nlm.nih.gov/gene/?term=cpxm2 (accessed on 14 January 2022)). This indicates that CPXM2 may play an important biological role. However, its distinct (patho-)physiological function is widely unknown.

High blood pressure is one of the most common causes of heart hypertrophy [13-15]. Additionally, LVH can result from athletic training [16] associated with physiologic higher plasma cardiac biomarkers, such as troponin I [17]. On the other hand, increased heartwall thickness can also develop independent from high blood pressure due to primary heart diseases, e.g., hypertrophic cardiomyopathy [18] or cardiac amyloidosis [19,20]. The most prevalent causes of LVH are summarized in Figure 1. Mechanical stress evokes altered expression patterns in cardiac myocytes [21]. Various z-disc-associated proteins are involved in this process called mechanotransduction, such as PDZ and LIM domain 3 (Pdlim3; PDZ stands for postsynaptic density 95, discs large, and zonula occludens-1; LIM was originally described in the proteins LIN-11, Isl1m, and MEC-3), also known as actinin-associated LIM protein (ALP) [22].

Primary hypertension

Secondary hypertension

(e.g., renal artery stenosis)

Aortic valve stenosis

Hypertrophic cardiomyopathy

Infiltrative cardiac processes

(e.g., Amyloidosis, Fabry disease)

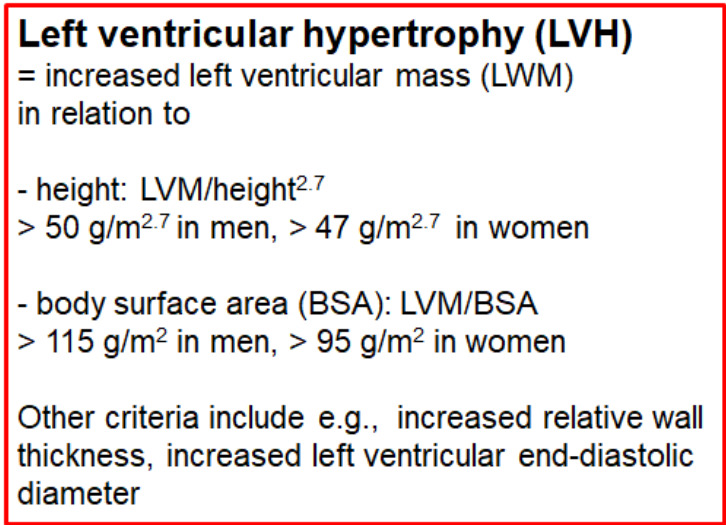

Figure 1. Different (patho-)physiologic conditions that can lead to left ventricular hypertrophy (LVH) in humans. Various CVDs as well as athletic training are associated with LVH. According to the American Society of Echocardiography and the European Association of Cardiovascular Imaging, $\mathrm{LVH}$ is defined as an increased left ventricular mass (LVM) in relation with height or body surface area. LVH can be determined via echocardiography or cardiac magnetic resonance imaging.

Micro (mi)RNAs are short ( 22 nucleotides long), single-stranded, non-coding RNAs $[23,24]$. They act as posttranscriptional regulators of gene expression via binding to regulatory sequences in the $3^{\prime}$-untranslated region $\left(3^{\prime} \mathrm{UTR}\right)$ of their corresponding target messenger (m)RNAs, thus leading to either repression of the translation or degradation of the target mRNA [25]. Various relevant processes involved in the development of CVDs, such as proliferation, apoptosis, inflammation, and fibrosis are influenced by miRNAs [26-31]. For example, miRNA (miR)-29b attenuated organ fibrosis in the cardiovascular system, and other tissues [32-36] via inhibiting the expression of collagens and other extracellular matrix proteins [37]. Members of the miR-15 family were also identified 
to be involved in cardiac diseases [38-40]. Amongst other things, miR-15 family members mediated a protective effect against heart hypertrophy and fibrosis via the repression of the transforming growth factor $\beta$ (TGF $\beta$ ) pathway [41]. Moreover, miRNAs themselves can be downregulated by long non-coding RNAs (lncRNAs) [42]. Interactions on the lncRNA-miRNA axis seem to play an important role in the pathophysiology of CVDs and may imply novel targeted therapies in this field [43-45]. Additionally, miRNAs can serve as useful diagnostic markers for various diseases [46-49].

In this study, we identified miRNA candidates able to regulate the expression of CPXM2 on a posttranscriptional level. Here, we showed a significant reduction of CPXM2 mRNA and protein in rat cardiomyocytes after transfection with miRNA-29b, miRNA497, and miRNA-195, respectively. With a dual luciferase reporter assay, we were able to confirm a direct interaction between miRNA-29b, and miRNA-497, respectively, with their in silico-predicted binding sides in the $3^{\prime} \mathrm{UTR}$ of the CPXM2 mRNA. Our data provide new insights into the expression control of CPXM2 in the context of its potential functional role in cardiovascular biology.

\section{Results}

\subsection{CPXM2 Is Expressed in Rat Cardiac Cells}

Immunofluorescence analysis revealed that CPXM2 was expressed in H9C2 rat cardiomyocytes (Figure 2A-C). In H9C2 cells, CPXM2 was co-localized with the z-discassociated protein Pdlim3. Western blot analysis confirmed the presence of CPXM2 protein in H9C2 (Figure 2D).

A

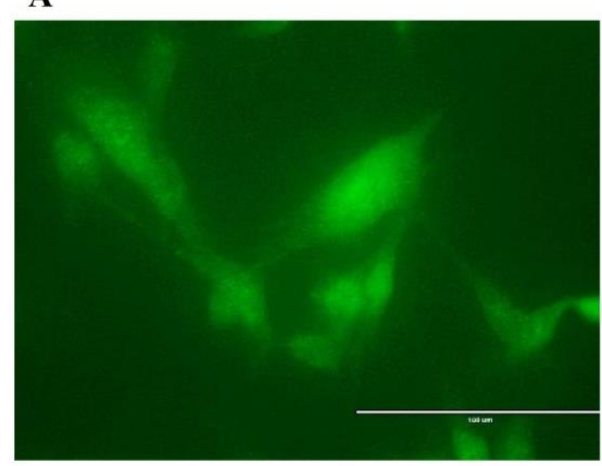

B

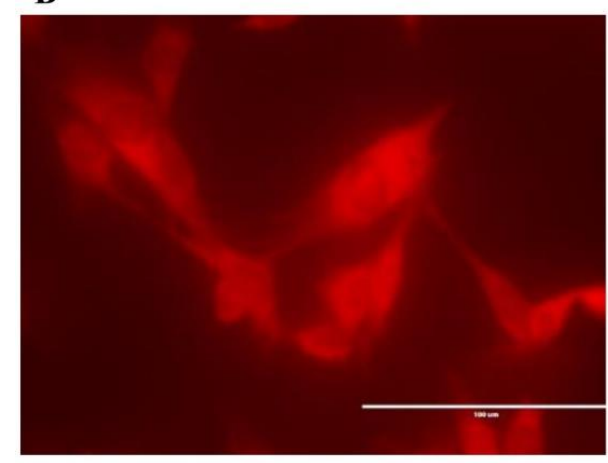

C

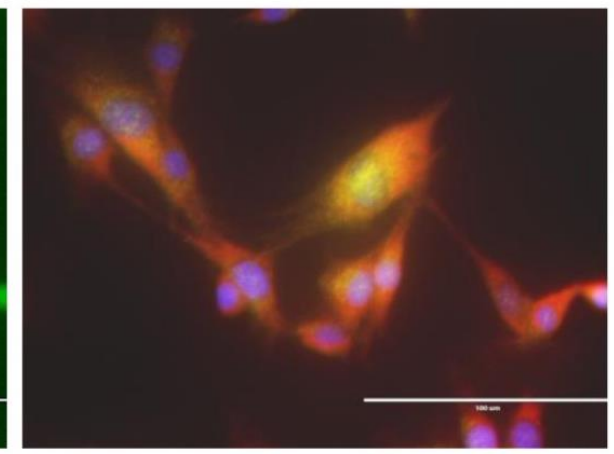

D

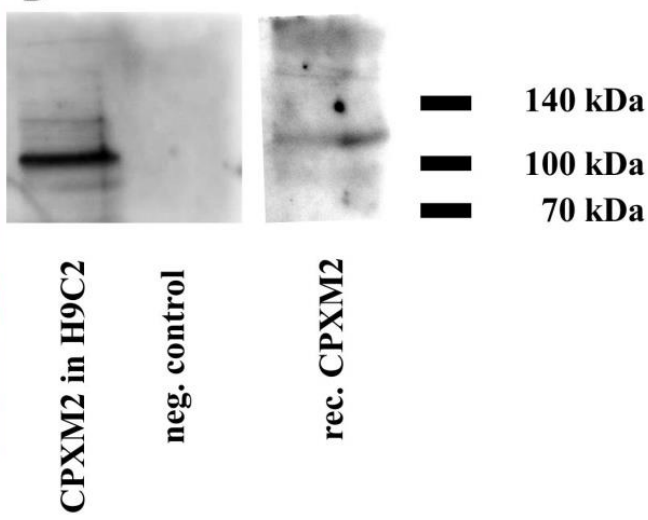

Figure 2. Expression of CPXM2 and Pdlim3 in rat cardiomyocytes. H9C2 cells were fixed and doublelabelled for confocal indirect immunofluorescence microscopy with the polyclonal (A) anti-CPXM2 and (B) anti-Pdlim3 antibodies. In the overlay image (C) intracellular co-localisation of CPXM2 and Pdlim3 in rat cardiomyocytes is depicted. Nuclear DNA was stained with DAPI (shown in blue). In (D) the CPXM2 protein expression in $\mathrm{H} 9 \mathrm{C} 2$ as well as a positive control (human recombinant CPXM2) and negative control (empty well) are shown. Bar $=100 \mu \mathrm{m}$. 
2.2. Identification of miR-29b, mir-195, and miR-497 as Candidates for Posttranscriptional CPXM2 Expression Control

Using several independent miRNA databases, approximately 20 different miRNAs were predicted to potentially bind to the $3^{\prime} \mathrm{UTR}$ of CPXM2 (data not shown). For three of them, miR-29b, miR-195, and miR-497, structural in silico analysis of the miRNA/target mRNA interaction indicated a possible formation of regulatory or stabilizing structures [24]. MiR-29b and mit-497 showed two important attributes necessary for the building of a stable miRNA/target mRNA complex: a perfect complementarity of miRNA bases 2-8 (seed region) with the corresponding $\mathrm{mRNA}$ sequences and the existence of a central bulge in the miRNA/target mRNA complexes (Figure 3A,B). The miR-195/CPXM2 3'UTR duplex exhibited only the presence of a central bulge, but the seed region of miR-195 was not perfectly complementary to the corresponding mRNA sequence (Figure 3C).

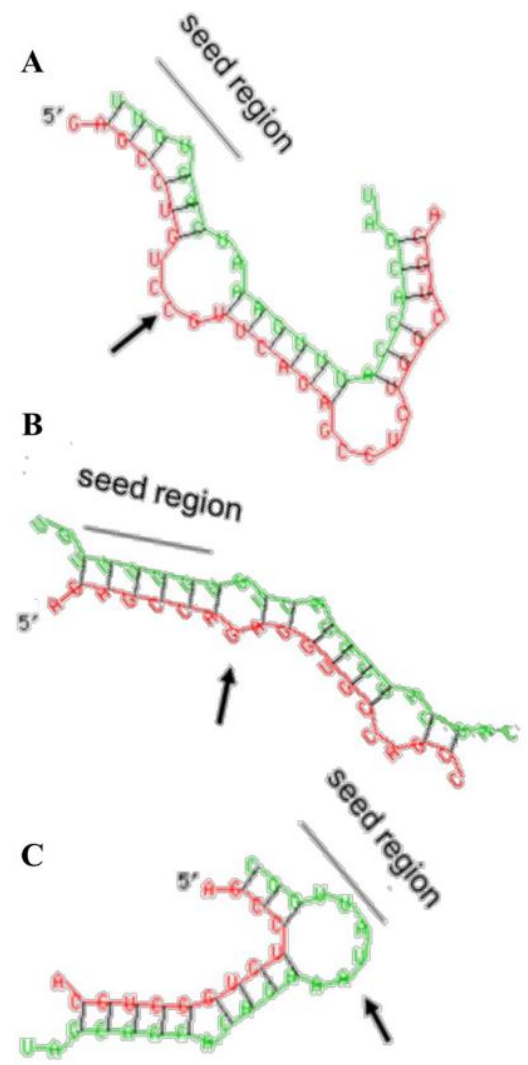

Figure 3. Structural in silico analysis of the miRNA/target mRNA interaction. Computational models of miRNA/mRNA interaction between (A) miR-29b, (B) miR-497, and (C) miR-195, respectively, with a corresponding sequence in the $3^{\prime} \mathrm{UTR}$ of CPXM2 mRNA. (green) miRNA; (red) CPXM2 mRNA 3'UTR sequence; (seed region) miRNA nucleotides 2-8; (arrow) central bulge.

\subsection{MiR-29b, mir-195, and miR-497 Suppressed the Expression of CPXM2}

To determine whether the miRNA candidates acted as posttranscriptional regulators of CPXM2 expression in cardiac cells, we transfected H9C2 with miR-29b, miR-195, miR-497, and negative control miRNA mimics, respectively. Treatment of cells with all three miRNA candidates significantly reduced the CPXM2 mRNA expression after $48 \mathrm{~h}$ (Figure $4 \mathrm{~A}$ ). A comparable effect was also found on protein level $48 \mathrm{~h}$ after transfection. Compared to the controls, CPXM2 protein expression was significantly reduced in H9C2 by miR-29b, miR-195, and miR-497, respectively (Figure 4B). 
A

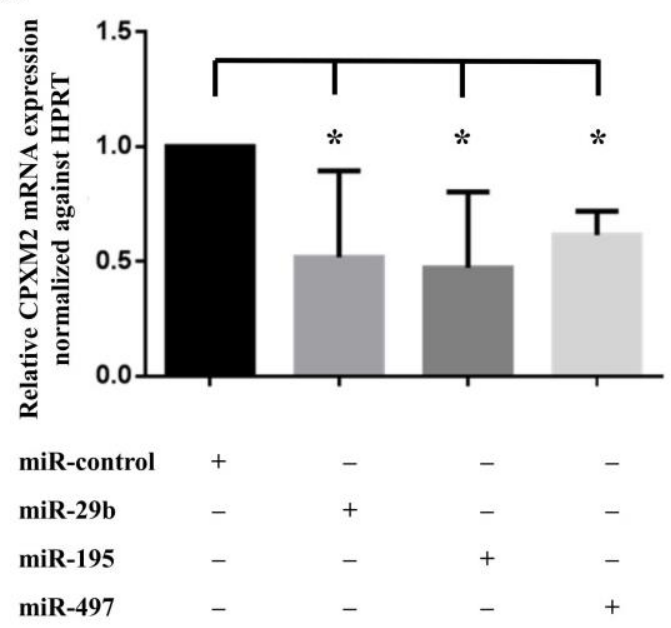

B
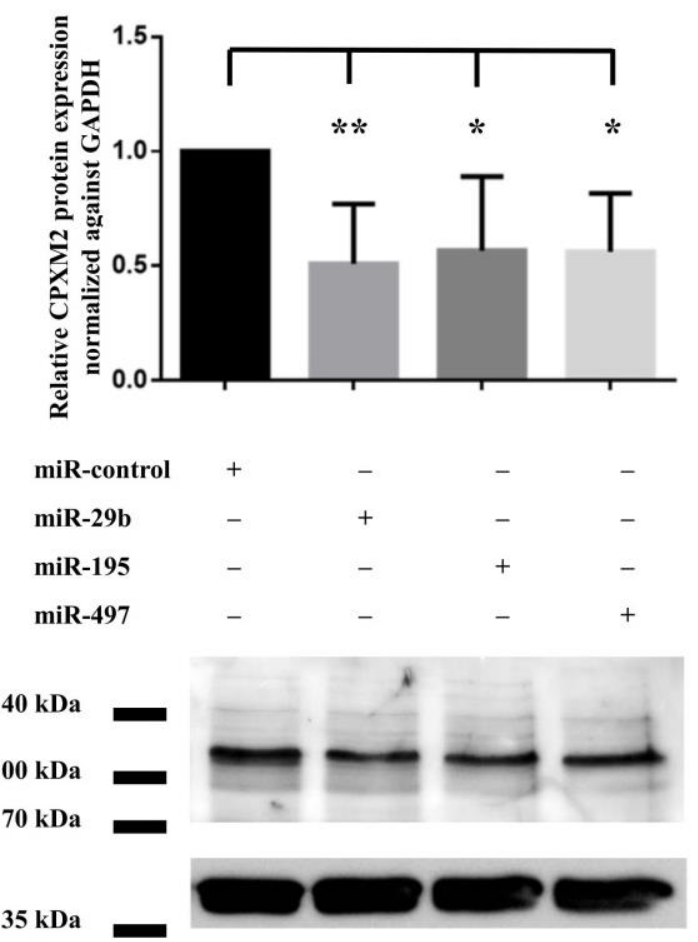

Figure 4. Impact of miR-29b, miR-195, and miR-497 on CPXM2 expression in H9C2 cells. Shown is the relative reduction of CPXM2 (A) mRNA and (B) protein expression in H9C2 $48 \mathrm{~h}$ after transfection with miR-29b, miR-195, miR-497, or a negative control miRNA mimics (miR-control), respectively. CPXM2 mRNA expression was normalized against HPRT. CPXM2 protein expression was normalized against GAPDH. Data were presented as relative $\left(x\right.$-fold) expression change. $\left({ }^{*}\right) p<0.05$; $\left.{ }^{* *}\right) p<0.01 ; n \geq 3$.

\subsection{MiR-29b, and miR-497 Inhibit CPXM2 Expression through Direct Binding to Regulatory} Sequences in the 3'UTR of CPXM2 mRNA

Dual luciferase reporter assays were performed to analyse whether the inhibitory impact of the miRNA candidates on CPXM2 was mediated by direct interaction with the 3'UTR of CPXM2 mRNA. Co-transfection of H9C2 with miR-29b or miR-497, respectively, and luciferase reporter vector containing the $3^{\prime} \mathrm{UTR}$ of CPXM2 led to a significant reduction of luciferase activity, compared to cells treated with negative control miRNA mimics (Figure 5A). For miR-195, no significant effect on luciferase activity was detected (Figure 5A).

To verify that the effect of candidate miRNAs on the luciferase activity was due to direct binding to the predicted sides in the CPXM2 $3^{\prime} \mathrm{UTR}$, we mutated the corresponding binding sides and repeated the experiment with the mutated vectors. Mutation of predicted binding sides completely abolished the inhibitory impact of miR-29b and miR-497 on luciferase activity in this experimental setting (Figure 5B). 
A

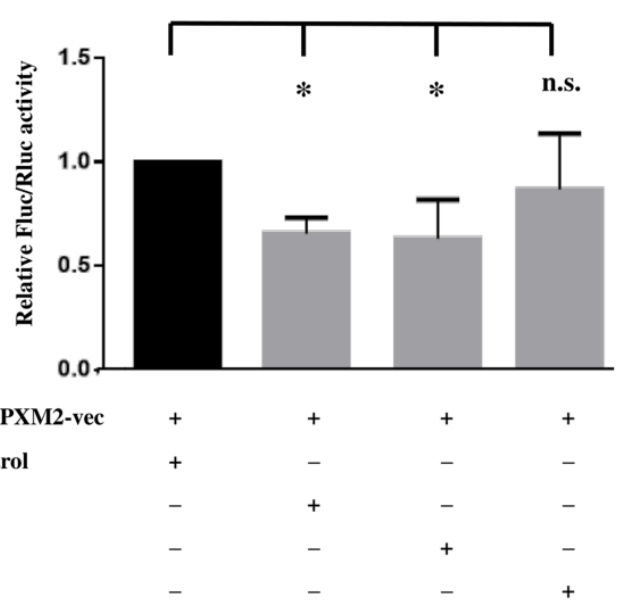

B

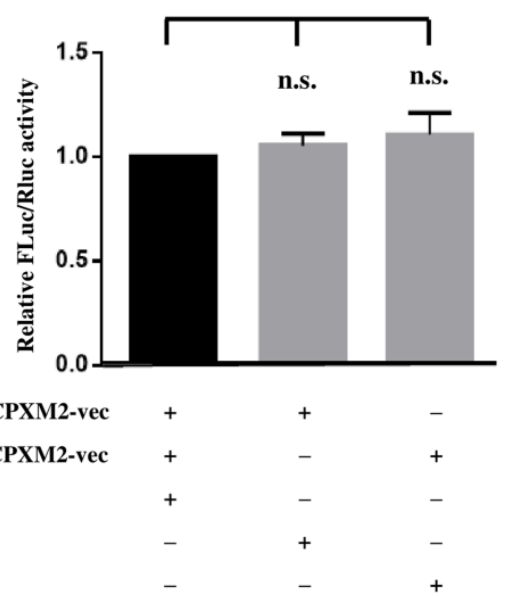

Figure 5. Dual luciferase reporter assay in H9C2. (A) Shown is the influence of miR-29b, miR-497, and miR-195, respectively, on the relative firefly luciferase activity of the miRNA $3^{\prime}$ UTR target clone pEZX-MT06, containing the 3'UTR of CPXM2 (3'UTR-CPXM2-vec) $48 \mathrm{~h}$ after transfection. (B) Depicts the impact of miR-29b and miR-497 on the relative firefly luciferase activity, respectively, containing the 3'UTR of CPXM2 with mutated binding sides for miR-29b (mut-29b-3'UTR-CPXM2vec), or miR-497 (mut-497-3'UTR-CPXM2-vec), respectively, 48 h after transfection. Firefly luciferase activity was normalized against renilla luciferase activity. $\left(^{*}\right) p<0.05$; (n.s.) no significant difference; $n \geq 3$; FLuc, firefly luciferase activity; RLuc, renilla luciferase activity; miR-control, negative control miRNA mimics.

\section{Discussion}

Although CPXM2 was first described more than 20 years ago [6], there is still little evidence about its expression control and biological role. In the present study, we determined its expression and localization in $\mathrm{H} 9 \mathrm{C} 2$ rat cardiomyocytes, representing a relevant in vitro model. Moreover, we characterized the impact of three candidate miRNAs on the posttranscriptional control of CPXM2 expression in H9C2 cells. Concerning the evolutionary conservation of CPXM2 among different species, our findings should be applicable to human cardiomyocytes as well. To verify this, future studies should be carried out.

\subsection{CPXM2 Is Expressed in Rat Cardiomyocytes and Co-Localized with Pdlim3}

Immunofluorescence and Western blot analysis showed that CPXM2 was expressed in rat cardiomyocytes. This is consistent with the findings of Grabowski et al. who explored CPXM2 in the cardiac tissue of rats, mice, and humans [7,50]. Furthermore, we demonstrated the co-localisation of CPXM2 with Pdlim3 in H9C2 (Figure 2A-C). Pdlim3 is a $\mathrm{z}$-disc protein which plays an important role in signal transduction, cell proliferation and cytoskeleton assembly in cardiac myocytes [51,52]. Lodder et al. associated elevated Pdlim3 levels with increased collagen deposition in the heart, a process involved in fibrosis in the context of cardiac disease [53]. Considering its co-localisation with Pdlim3, CPXM2 could potentially be involved in Pdlim3-mediated effects during the development of heart hypertrophy and fibrosis.

CPXM2, similar to two other related proteins sharing a high sequence homology with CPXM2 (CPXM1 and AEBP1) contains a discoidin domain, which is not present in any other metallocarboxypeptidase family member $[10,11]$. Discoidin motive can be found in many eukaryotic and prokaryotic proteins. It usually serves as a binding domain for different ligands, such as growth factors, galactose or collagens [54]. Both CPXM1 and AEBP1 are able to bind collagen [11,55]. Therefore, it is conceivable that CPXM2 may also interact with collagen, which - in turn-may affect cardiac fibrosis. However, further experiments are needed to test the ability of CPXM2 to bind collagen and to examine the possible involvement of CPXM2 in the process of cardiac fibrosis. 


\subsection{CPXM2 Expression Is Directly Regulated via miR-29b and via miR-497}

MiRNAs influence many cellular functions via suppressing the generation of their corresponding target proteins on a posttranscriptional level [56]. MiRNAs have been associated with the pathogenesis of several cardiovascular pathologies, such as heart hypertrophy and fibrosis [36,57-61]. Here, we showed for the first time that miR-29b, as well as miR-497, reduced CPXM2 expression in $\mathrm{H} 9 \mathrm{C} 2$ through its specific binding to the 3'UTR of CPXM2 mRNA.

Other groups reported elevated miRNA-29b levels to be associated with antifibrotic effects in the heart and other tissues [32,34,62-65]. For example, Monaghan et al. showed that local delivery of miR-29b into heart tissue shortly after myocardial infarction positively influenced postischemic cardiac remodelling in mice [32]. Zhang et al. demonstrated that miR-29b overexpression prevented angiotensin II-induced cardiac fibrosis by targeting the TGF $\beta$ pathway [65]. Qin et al. also found miR-29b to be involved in TGF $\beta$ signalling. MiR-29 reduced TGF $\beta$-mediated renal fibrosis in mice with obstructive nephropathy [34].

The other miRNA candidate from this study, miR-497, was also shown to play an important role in the development of CVDs in previous studies [39,60]. Xiao et al. described in 2016 that treatment of primary mouse cardiomyocytes with angiotensin II led to lowered miR-497 levels in an in vitro model of cardiac hypertrophy [60]. Moreover, miR-497 overexpression led to a decrease in various hypertrophy markers, such as cell area and atrial natriuretic peptides.

Together, these studies indicate a potential role of miR-29b and miR-497 in fibrosis, cellular remodelling, and in the development of heart hypertrophy, which may be potentially mediated via modulating CPXM2 expression (Figure 6). However, further studies should be performed to explore the molecular pathways in which CPXM2 may be involved to better understand its biological function. Deeper knowledge about the pathophysiological role of CPXM2 in the development of cardiac hypertrophy and fibrosis could help us to implement novel targeted therapies for these conditions. MiRNAs, in general, have been shown to act as potential therapeutic agents $[66,67]$. For example, Ban et al. demonstrated miRNA-497 to accelerate wound healing in diabetic mice after local injection [68]. Thus, our findings could contribute to the development of future miRNA-based therapeutics for hypertension-induced CVDs.

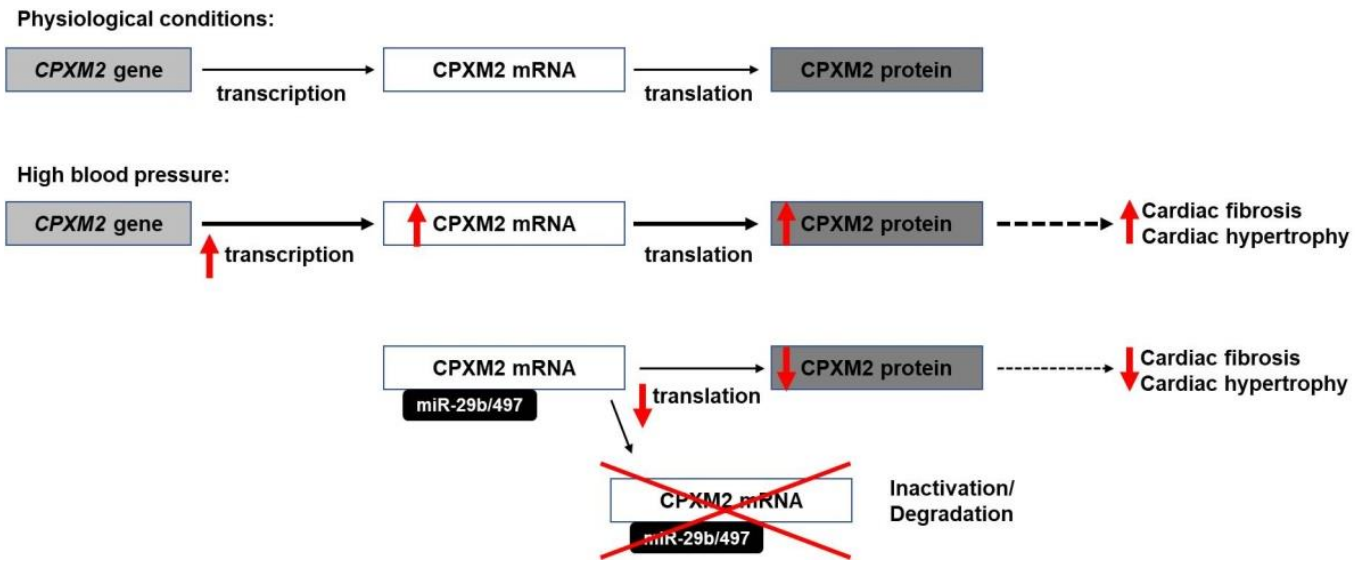

Figure 6. Possible effects of CPXM2 expression regulation via miRNA-29b and miRNA-497. According to Grabowski at al., CPXM2 is overexpressed under high blood pressure conditions. miRNAmediated CPXM2 downregulation may reduce cardiac hypertrophy and fibrosis. Red arrow indicates an increase $(\uparrow)$ or a decrease $(\downarrow)$.

In addition to the direct effects of miR-29b and miR-497, we also found a significant inhibitory effect of miR-195 on the CPXM2 expression in H9C2. However, in contrast to the other tested miRNA candidates, miR-195 did not reduce luciferase activity, indicating no direct interaction of miR-195 with the CPXM2 mRNA (Figure 5A). This finding is in line with 
the lack of perfect base pairing between the seed region of miR-195 and the corresponding sequence in the CPXM2 3'UTR revealed by our in silico analysis (Figure 3C). Possibly, miR-195 reduced the CPXM2 expression via indirect effects. Zhang et al. show miR-195 to be involved in the TGF $\beta$ signalling pathway, thus attenuating cardiac hypertrophy [69]. It may be possible that miR-195 influences the CPXM2 expression via the TGF $\beta$ signalling pathway. However, further research would be needed to verify this hypothesis.

In addition, more experiments should be carried out to better understand the role of CPXM2 in cardiac tissue. Until now, we were not able to show a functional influence of miRNA-induced CPXM2 downregulation on cell signalling in $\mathrm{H} 9 \mathrm{C} 2$ cells. Our pilot studies (data not shown) did not reveal a significant impact of the tested miRNA candidates via the transfection of $\mathrm{H} 9 \mathrm{C} 2$ on the phosphorylation state of factors involved in the phosphatidylinositol 3-kinase/protein kinase B/mammalian target of rapamycin (PI3K/Akt/mTOR) pathway, which could indicate a potential influence of CPXM2 on cell survival and proliferation [70]. Further research is necessary to examine the involvement of CPXM2 on cell signalling or the other biological effects of CPXM2 in cardiomyocytes. Such analyses are planned for future studies.

\section{Materials and Methods}

\subsection{Cell Culture}

Rat cardiomyocytes (H9C2) were cultured in Dulbecco's Modified Eagle Medium (DMEM) with $10 \%$ foetal bovine serum (FBS), and 1\% penicillin/streptomycin, all purchased from Biochrom $\mathrm{GmbH}$, Berlin, Germany. $\mathrm{H} 9 \mathrm{C} 2$ were kept at $37^{\circ} \mathrm{C}$ and in a humidified $5 \% \mathrm{CO}_{2}$ atmosphere. Before transfection, cells were starved with FBS-free DMEM for at least $12 \mathrm{~h}$. Transfection of $\mathrm{H} 9 \mathrm{C} 2$ was performed using $200 \mathrm{nM}$ miRNA-mimics for miR-29b, miR-195, miR-497, and nonsense miRNA control (miR-control), all provided by Sigma-Aldrich Chemie GmbH by Merck, Munich, Germany. Lipofectamine ${ }^{\circledR} 2000$ was supplied by Thermo Fisher Scientific, Carlsbad, CA, USA. Transfection efficiency, tested via fluorescence-activated cell sorting $6 \mathrm{~h}$ after transfection with $200 \mathrm{nM}$ Dy547 transfection control (Dharmacon, Lafayette, CO, USA), was $62 \%$ in $\mathrm{H} 9 \mathrm{C} 2$.

\subsection{In Silico Analysis}

Potential miRNA candidates capable of regulating the CPXM2 expression were identified using the miRNA databases TargetScan (http:/ / www.TargetScan.org), miRDB (http: //miRDB.org), and microRNA.org-Targets and Expression (http://www.microRNA.org), all accessed on 18 April 2016. Structural in silico analysis of the miRNA/mRNA interaction was performed using the RNAhybrid 2.2 database (https:/ / bibiserv.cebitec.uni-bielefeld. de/rnahybrid (accessed on 20 April 2016)).

\subsection{Immunofluorescence Staining}

For immunofluorescence analysis, $\mathrm{H} 9 \mathrm{C} 2$ cells were fixated with $4 \%$ formaldehyde and permeabilized with $0.5 \%$ Triton X-100 for $10 \mathrm{~min}$. Three washing steps with $1 \times$ phosphatebuffered saline (PBS) were performed to remove residual formaldehyde. To prevent unspecific binding, cells were blocked for $20 \mathrm{~min}$ at room temperature in PBS with 5\% FBS and $0.1 \%$ Triton X100. Samples were then directly incubated with polyclonal rabbit anti-rat CPXM2 antibodies (Thermo Fisher, Carlsbad, CA, USA) 1:100 for $1 \mathrm{~h}$ at room temperature. For detection, after three washings steps in $1 \times$ PBS, fluorescein isothiocyanate (FITC)labelled goat anti-rabbit antibodies (\#12-507, Millipore by Merck, Darmstadt, Germany) were used in a 1:200 dilution for $1 \mathrm{~h}$ at room temperature in the dark. Next, after two washings steps in $1 \times$ PBS, samples were incubated with polyclonal ALEXA FLUOR ${ }^{\circledR} 594$ conjugated rabbit anti-rat Pdlim3 antibodies (\#bs-2928R-A594, Bioss, Woburn, MA, USA) in a 1:200 dilution for $1 \mathrm{~h}$ at room temperature in the dark. Nuclear DNA was stained with 4',6-Diamidino-2-Phenylindole (DAPI, \#D1306, Thermo Fisher, Carlsbad, CA, USA), 1:5000, for $10 \mathrm{~min}$ at room temperature in the dark. Immunofluorescence was detected with a 
confocal microscope (Leica TCS SPE, Wetzlar, Germany) and analysed by the EVOS ${ }^{\circledR}$ FL Auto Imaging System (Thermo Fisher, Carlsbad, CA, USA).

\subsection{Quantitative Real-Time Polymerase Chain Reaction (RT-qPCR)}

Total RNA was isolated $48 \mathrm{~h}$ after transfection via the universal RNA purification kit (Roboklon GmbH, \#E3598-02, Berlin, Germany). Then, $1 \mu \mathrm{g}$ of isolated RNA was reverse transcribed using the high-capacity cDNA reverse transcription kit (Thermo Fisher Scientific, \#4368814, Carlsbad, CA, USA) under conditions: $65^{\circ} \mathrm{C}, 5 \mathrm{~min} ; 25^{\circ} \mathrm{C}, 10 \mathrm{~min} ; 37^{\circ} \mathrm{C}$, $120 \mathrm{~min} ; 85^{\circ} \mathrm{C}, 5 \mathrm{~min}$. Subsequent, RT-qPCR was performed by using a 7500 Fast Real-Time PCR System (Thermo Fisher Scientific, Carlsbad, CA, USA) and the Fast SYBR ${ }^{\circledR}$ Green Master Mix (Applied Biosystems, Darmstadt, Germany) for measurement of CPXM2 and hypoxanthine phosphoribosyltransferase (HPRT), following the manufacturer's protocol. Primers CPXM2-f/CPXM2-r (CATCCCTGAGTGGTTTCTGTCTG/TGCTACAACCAGCTCACCCC) and HPRT-f/HPRT-r (CTCATGGACTGATTATGGACAGGACT/TCCAGCAGGTCAGCAA AGAAC) were used. PCR temperature conditions: $95^{\circ} \mathrm{C}, 20 \mathrm{~s} ; 50$ cycles $95^{\circ} \mathrm{C}, 3 \mathrm{~s} ; 60^{\circ} \mathrm{C}$, $30 \mathrm{~s}$. Relative quantification was performed using the $\Delta \Delta$-cq method [71].

\subsection{Western Blotting}

Proteins were isolated from H9C2 $48 \mathrm{~h}$ after transfection. Western blot analyses of protein samples were carried out as described before [72]. In brief, protein samples were separated by sodium dodecyl sulfate polyacrylamide gel electrophoresis (SDS-PAGE) and transferred to polyvinylidene difluoride (PVDF) membrane (Carl Roth GmbH, Karlsruhe, Germany). For detection, specific rabbit anti-rat antibodies against CPXM2 (Thermo Fisher, Carlsbad, CA, USA) 1:300, and mouse anti-rat antibodies against glyceraldehyde 3-phosphate dehydrogenase (GAPDH, Calbiochem by Merck, Darmstadt, Germany) 1:500 were used (incubation overnight at $4{ }^{\circ} \mathrm{C}$ ). Subsequently, the samples were incubated with corresponding secondary goat anti-rabbit antibodies (Sc-2004, Sigma-Aldrich Chemie GmbH by Merck, Munich, Germany) in a 1:5000 dilution and goat anti-mouse antibodies (\# A4416-1ML, Sigma-Aldrich Chemie GmbH by Merck, Munich, Germany) in a 1:10000 dilution for $1 \mathrm{~h}$ at room temperature in the dark. Human recombinant CPXM2 protein (Abnova, Taipei, Taiwan) was used as a positive control. Blots were visualized and quantified by using FUSION FX7 (Peqlab Biotechnologie GmbH, Erlangen, Deutschland). Western blot results were quantified via Gel-Pro Analyzer software version 4.0.00.001 (Media Cybernetics, Bethesda, MD, USA).

\subsection{Dual Luciferase Reporter Assay}

Dual luciferase reporter assays were preformed using a miRNA $3^{\prime}$ UTR target clone pEZX-MT06, containing the 3'UTR of CPXM2 (\# HmiT002050-MT06) and the negative control vector (\# CmiT000001-MT01), both supplied by GeneCopoeia, Rockville, MD, USA. Furthermore, two $3^{\prime}$ UTR clones with a mutated binding side for miR-29b, or miR-497, respectively, were prepared using the Q $5^{\circledR}$ Site-Directed Mutagenesis Kit (New England BioLabs, Ipswich, MA, USA) according to the manufacturer's protocol. H9C2 were cotransfected with $200 \mathrm{nM} \mathrm{miR-29b}$, miR-195, or miR-497 mimics, and $200 \mathrm{ng}$ of the luciferase reporter vector (wild type or mutated vectors, respectively) or the empty control vector in 96-well plates in total volume $100 \mu \mathrm{L}$ of DMEM. Then, $48 \mathrm{~h}$ after transfection the luciferase reporter assay (Dual-Glo ${ }^{\circledR}$ Luciferase Assay System, Promega, Madison, WI, USA) was performed, following the manufacturer's instructions.

\subsection{Statistical Analysis}

All data were expressed as mean \pm SEM. Data were analysed by Student's $t$-test or one-way ANOVA, as appropriate. Statistical analyses were performed using GraphPad Prism v4.03 (GraphPad Software, Inc., La Jolla, CA, USA). A probability value $(p) \leq 0.05$ was regarded as significant. 


\section{Conclusions}

In summary, we showed for the first time that CPXM2 is expressed in rat cardiomyocytic cells. Moreover, we demonstrated miR-29b and miR-497 to regulate CPXM2 expression on a posttranscriptional level. This was mediated via the direct interaction of these miRNAs with the regulatory elements within the $3^{\prime} \mathrm{UTR}$ of CPXM2 mRNA. These novel findings may help to shed more light on the-so far-widely unexplored expression control of CPXM2 and may help to further characterize the functional role of this factor in the context of arterial hypertension-induced heart hypertrophy and cardiac fibrosis. Understanding of the pathophysiological function of CPXM2 in cardiac tissue could lead to development of future targeted therapies for CVDs.

Author Contributions: Conceptualization, J.S. and A.E.; formal analysis, J.S. and A.E.; funding acquisition, R.K.; investigation, J.S., K.B., A.G., M.O., C.P. and A.E.; methodology, K.B., C.P. and A.E.; resources, R.K.; supervision, R.K. and A.E.; writing—original draft, J.S.; writing—review and editing, K.B., R.K. and A.E. All authors have read and agreed to the published version of the manuscript.

Funding: This study was supported by the Deutsche Hochdruckliga (DHL) as Hypertensiologie Professur to Reinhold Kreutz and funded by the Deutsche Forschungsgemeinschaft (DFG, German Research Foundation) (project number 394046635-SFB 1365 and KR1152/3-1), DZHK (81X2100120) and Bundesministerium für Bildung und Forschung, Nationales Genomforschungsnetz, Herzkreislaufnetz in NGFN plus Grant 01GS0839 in Germany. The article processing charges were paid from the Open Access Fund of the Charite Library.

Institutional Review Board Statement: Not applicable.

Informed Consent Statement: Not applicable.

Data Availability Statement: The datasets generated and/or analysed during the current study are available from the corresponding author on reasonable request.

Acknowledgments: We thank Anja Brehm, Petra Karsten, and Sarah Podlich for technical and experimental support.

Conflicts of Interest: The authors declare that there are no conflict of interest.

\section{References}

1. $\quad$ Burden of Disease Study 2013. Lancet 2015, 385, 117-171.

2. Xu, J.; Murphy, S.L.; Kockanek, K.D.; Arias, E. Mortality in the United States, 2018. NCHS Data Brief. 2020, 355, 1-8.

3. Aryan, L.; Younessi, D.; Zargari, M.; Banerjee, S.; Agopian, J.; Rahman, S.; Borna, R.; Ruffenach, G.; Umar, S.; Eghbali, M. The Role of Estrogen Receptors in Cardiovascular Disease. Int. J. Mol. Sci. 2020, 21, 4314. [CrossRef] [PubMed]

4. Fuchs, F.D.; Whelton, P.K. High Blood Pressure and Cardiovascular Disease. Hypertension 2020, 75, 285-292. [CrossRef]

5. Brown, S.K.; Sheikh, A.M.; Guzik, T.J. Cardiovascular Research at the frontier of biomedical science. Cardiovasc. Res. 2020, 116, e83-e86. [CrossRef]

6. Xin, X.; Day, R.; Day, R.; Dong, W.; Lei, Y.; Fricker, L.D. Identification of Mouse CPX-2, a Novel Member of the Metallocarboxypeptidase Gene Family: cDNA Cloning, mRNA Distribution, and Protein Expression and Characterization. DNA Cell Biol. 1998, 17, 897-909. [CrossRef]

7. Grabowski, K.; Herlan, L.; Eisenreich, A.; Schulz, A.; Müller, D.N.; Plehm, R.; Bader, M.; Kreutz, R. [OP.8C.01] A novel candidate gene identified in stroke-prone spontaneously hypertensive rats has a major impact on adverse left ventricular remodeling in salt-induced hypertension. J. Hypertens. 2016, 34, e102. [CrossRef]

8. Zhao, X.; Li, R.; Li, R.; Wang, Q.; Wu, M.; Wang, Y. Overexpression of carboxypeptidase X M14 family member 2 predicts an unfavorable prognosis and promotes proliferation and migration of osteosarcoma. Diagn Pathol. 2019, 14, 118. [CrossRef]

9. Niu, G.; Yang, Y.; Ren, J.; Song, T.; Hu, Z.; Chen, L.; Hong, R.; Xia, J.; Ke, C.; Wang, X. Overexpression of CPXM2 Predicts an Unfavorable Prognosis and Promotes the Proliferation and Migration of Gastric Cancer. Oncol. Rep. 2019, 42, 1283-1294. [CrossRef]

10. Reznik, S.E.; Fricker, L.D. Carboxypeptidases from A to Z: Implications in embryonic development and Wnt binding. Cell Mol. Life Sci. 2001, 58, 1790-1804. [CrossRef]

11. Kim, Y.H.; O'Neill, H.M.; Whitehead, J.P. Carboxypeptidase X-1 (CPX-1) is a secreted collagen-binding glycoprotein. Biochem. Biophys. Res. Commun. 2015, 468, 894-899. [CrossRef] 
12. Somma, G.; Alger, H.M.; McGuire, R.M.; Kretlow, J.D.; Ruiz, F.R.; Yatsenko, S.A.; Stankiewicz, P.; Harrison, W.; Funk, E.; Bergamaschi, A.; et al. Head bobber: An insertional mutation causes inner ear defects, hyperactive circling, and deafness. J. Assoc. Res. Otolaryngol. 2012, 13, 335-349. [CrossRef]

13. Grabowski, K.; Riemenschneider, M.; Schulte, L.; Witten, A.; Schulz, A.; Stoll, M.; Kreutz, R. Fetal-adult cardiac transcriptome analysis in rats with contrasting left ventricular mass reveals new candidates for cardiac hypertrophy. PLoS ONE 2015, 10, e0116807. [CrossRef]

14. Yildiz, M.; Oktay, A.A.; Stewart, M.H.; Milani, R.V.; Ventura, H.O.; Lavie, C.J. Left ventricular hypertrophy and hypertension. Prog. Cardiovasc. Dis. 2020, 63, 10-21. [CrossRef] [PubMed]

15. Bornstein, A.B.; Rao, S.S.; Marwaha, K. Left Ventricular Hypertrophy; StatPearls Publishing: Orlando, FL, USA, 2022.

16. Pavlik, G.; Kováts, T.; Kneffel, Z.; Komka, Z.; Radák, Z.; Tóth, M.; Nemcsik, J. Characteristics of the athlete's heart in aged hypertensive and normotensive subjects. J. Sports Med. Phys. Fit. 2021, 21, 126994. [CrossRef] [PubMed]

17. Mascia, G.; Pescetelli, F.; Baldari, A.; Gatto, P.; Seitun, S.; Sartori, P.; Pieroni, M.; Calò, L.; Della Bona, R.; Porto, I. Interpretation of elevated high-sensitivity cardiac troponin I in elite soccer players previously infected by severe acute respiratory syndrome coronavirus 2. Int. J. Cardiol. 2021, 326, 248-251. [CrossRef] [PubMed]

18. Mascia, G.; Olivotto, I.; Brugada, J.; Arbelo, E.; Di Donna, P.; Della Bona, R.; Canepa, M.; Porto, I. Sport practice in hypertrophic cardiomyopathy: Running to stand still? Int. J. Cardiol. 2021, 345, 77-82. [CrossRef]

19. Maurizi, N.; Rella, V.; Fumagalli, C.; Salerno, S.; Castelletti, S.; Dagradi, F.; Torchio, M.; Marceca, A.; Meda, M.; Gasparini, M.; et al. Prevalence of cardiac amyloidosis among adult patients referred to tertiary centres with an initial diagnosis of hypertrophic cardiomyopathy. Int. J. Cardiol. 2020, 300, 191-195. [CrossRef]

20. Lioncino, M.; Monda, E.; Palmiero, G.; Caiazza, M.; Vetrano, E.; Rubino, M.; Esposito, A.; Salerno, G.; Dongiglio, F.; D’Onofrio, B.; et al. Cardiovascular Involvement in Transthyretin Cardiac Amyloidosis. Heart Fail. Clin. 2022, 1, 73-87. [CrossRef]

21. Knöll, R.; Hoshijima, M.; Chien, K. Cardiac mechanotransduction and implications for heart disease. J. Mol. Med. 2003, 81, 750-756. [CrossRef]

22. Frank, D.; Frey, N. Cardiac Z-disc Signaling Network. J. Biol. Chem. 2011, 286, 9897-9904. [CrossRef]

23. Blahna, M.T.; Hata, A. Regulation of miRNA biogenesis as an integrated component of growth factor signaling. Curr. Opin. Cell Biol. 2013, 25, 233-240. [CrossRef] [PubMed]

24. Eisenreich, A.; Leppert, U. The impact of microRNAs on the regulation of tissue factor biology. Trends Cardiovasc. Med. 2014, 24, 128-132. [CrossRef] [PubMed]

25. Van Rooij, E. The Art of MicroRNA Research. Circ. Res. 2011, 108, 219-234. [CrossRef] [PubMed]

26. Olson, E.N. MicroRNAs as therapeutic targets and biomarkers of cardiovascular disease. Sci. Transl. Med. 2014, 6, 239 ps233. [CrossRef]

27. Eisenreich, A.; Rauch, U. Regulation of the Tissue Factor Isoform Expression and Thrombogenicity of HMEC-1 by miR-126 and miR-19a. Cell Biol. Res. Ther. 2013, 2, 124.

28. Lee, J.; Kang, H. Hypoxia Promotes Vascular Smooth Muscle Cell Proliferation through microRNA-Mediated Suppression of Cyclin-Dependent Kinase Inhibitors. Cells 2019, 8, 802. [CrossRef]

29. Li, Z.; Yi, N.; Chen, R.; Meng, Y.; Wang, Y.; Liu, H.; Cao, W.; Hu, Y.; Gu, Y.; Tong, C.; et al. miR-29b-3p protects cardiomyocytes against endotoxin-induced apoptosis and inflammatory response through targeting FOXO3A. Cell. Signal. 2020, 74, 109716. [CrossRef]

30. Sun, D.G.; Tian, S.; Zhang, L.; Hu, Y.; Guan, C.Y.; Ma, X.; Xia, H.F. The miRNA-29b Is Downregulated in Placenta During Gestational Diabetes Mellitus and May Alter Placenta Development by Regulating Trophoblast Migration and Invasion Through a HIF3A-Dependent Mechanism. Front. Endocrinol. 2020, 11, 169. [CrossRef]

31. Esteves, J.V.; Yonamine, C.Y.; Pinto-Junior, D.C.; Gerlinger-Romero, F.; Enguita, F.J.; Machado, U.F. Diabetes Modulates MicroRNAs 29b-3p, 29c-3p, 199a-5p and 532-3p Expression in Muscle: Possible Role in GLUT4 and HK2 Repression. Front. Endocrinol. 2018, 9, 536. [CrossRef]

32. Monaghan, M.G.; Holeiter, M.; Brauchle, E.; Layland, S.L.; Lu, Y.; Deb, A.; Pandit, A.; Nsair, A.; Schenke-Layland, K. Exogenous miR-29B Delivery Through a Hyaluronan-Based Injectable System Yields Functional Maintenance of the Infarcted Myocardium. Tissue Eng. Part A 2018, 24, 57-67. [CrossRef]

33. Xiao, J.; Meng, X.M.; Huang, X.R.; Chung, A.C.; Feng, Y.L.; Hui, D.S.; Yu, C.M.; Sung, J.J.; Lan, H.Y. miR-29 inhibits bleomycininduced pulmonary fibrosis in mice. Mol. Ther. 2012, 20, 1251-1260. [CrossRef]

34. Qin, W.; Chung, A.C.K.; Huang, X.R.; Meng, X.M.; Hui, D.S.C.; Yu, C.M.; Sung, J.J.Y.; Lan, H.Y. TGF- $\beta /$ Smad3 signaling promotes renal fibrosis by inhibiting miR-29. J. Am. Soc. Nephrol. 2011, 22, 1462-1474. [CrossRef] [PubMed]

35. Van Rooij, E.; Sutherland, L.B.; Thatcher, J.E.; DiMaio, J.M.; Naseem, R.H.; Marshall, W.S.; Hill, J.A.; Olson, E.N. Dysregulation of microRNAs after myocardial infarction reveals a role of miR-29 in cardiac fibrosis. Proc. Natl. Acad. Sci. USA 2008, 105, 13027-13032. [CrossRef]

36. García, R.; Salido-Medina, A.B.; Gil, A.; Merino, D.; Gómez, J.; Villar, A.V.; González-Vílchez, F.; Hurlé, M.A.; Nistal, J.F. SexSpecific Regulation of miR-29b in the Myocardium Under Pressure Overload is Associated with Differential Molecular, Structural and Functional Remodeling Patterns in Mice and Patients with Aortic Stenosis. Cells 2020, 9, 833. [CrossRef] 
37. Abonnenc, M.; Nabeebaccus, A.A.; Mayr, U.; Barallobre-Barreiro, J.; Dong, X.; Cuello, F.; Sur, S.; Drozdov, I.; Langley, S.R.; Lu, R.; et al. Extracellular matrix secretion by cardiac fibroblasts: Role of microRNA-29b and microRNA-30c. Circ. Res. 2013, 113, 1138-1147. [CrossRef] [PubMed]

38. Zhang, X.; Ji, R.; Liao, X.; Castillero, E.; Kennel, P.J.; Brunjes, D.L.; Franz, M.; Möbius-Winkler, S.; Drosatos, K.; George, I.; et al. MicroRNA-195 Regulates Metabolism in Failing Myocardium Via Alterations in Sirtuin 3 Expression and Mitochondrial Protein Acetylation. Circulation 2018, 137, 2052-2067. [CrossRef]

39. Li, X.; Zeng, Z.; Li, Q.; Xu, Q.; Xie, J.; Hao, H.; Luo, G.; Liao, W.; Bin, J.; Huang, X.; et al. Inhibition of microRNA-497 ameliorates anoxia/reoxygenation injury in cardiomyocytes by suppressing cell apoptosis and enhancing autophagy. Oncotarget 2015, 6, 18829-18844. [CrossRef]

40. Porrello, E.R.; Mahmoud, A.I.; Simpson, E.; Johnson, B.A.; Grinsfelder, D.; Canseco, D.; Mammen, P.P.; Rothermel, B.A.; Olson, E.N.; Sadek, H.A. Regulation of neonatal and adult mammalian heart regeneration by the miR-15 family. Proc. Natl. Acad. Sci. USA 2013, 110, 187-192. [CrossRef] [PubMed]

41. Tijsen, A.J.; van der Made, I.; van den Hoogenhof, M.M.; Wijnen, W.J.; van Deel, E.D.; de Groot, N.E.; Alekseev, S.; Fluiter, K.; Schroen, B.; Goumans, M.J.; et al. The microRNA-15 family inhibits the TGF $\beta$-pathway in the heart. Cardiovasc. Res. 2014, 104, 61-71. [CrossRef]

42. Mirzaei, S.; Zarrabi, A.; Hashemi, F.; Zabolian, A.; Saleki, H.; Ranjbar, A.; Seyed Saleh, S.H.; Bagherian, M.; Sharifzadeh, S.O.; Hushmandi, K.; et al. Regulation of Nuclear Factor-KappaB (NF-кB) signaling pathway by non-coding RNAs in cancer: Inhibiting or promoting carcinogenesis? Cancer Lett. 2021, 509, 63-80. [CrossRef] [PubMed]

43. Braga, L.; Ali, H.; Secco, I.; Giacca, M. Non-coding RNA therapeutics for cardiac regeneration. Cardiovasc. Res. 2021, 117, 674-693. [CrossRef]

44. Yan, Y.; Song, D.; Song, X.; Song, C. The role of lncRNA MALAT1 in cardiovascular disease. IUBMB Life 2020, 72, 334-342. [CrossRef] [PubMed]

45. Cheng, X.W.; Chen, Z.F.; Wan, Y.F.; Zhou, Q.; Wang, H.; Zhu, H.Q. Long Non-coding RNA H19 Suppression Protects the Endothelium Against Hyperglycemic-Induced Inflammation via Inhibiting Expression of miR-29b Target Gene Vascular Endothelial Growth Factor a Through Activation of the Protein Kinase B/Endothelial Nitric Oxide Synthase Pathway. Front. Cell. Dev. Biol. 2019, 7, 263. [PubMed]

46. Galeano-Otero, I.; Del Toro, R.; Guisado, A.; Díaz, I.; Mayoral-González, I.; Guerrero-Márquez, F.; Gutiérrez-Carretero, E.; Casquero-Domínguez, S.; Díaz-de la Llera, L.; Barón-Esquivias, G.; et al. Circulating miR-320a as a Predictive Biomarker for Left Ventricular Remodelling in STEMI Patients Undergoing Primary Percutaneous Coronary Intervention. J. Clin. Med. 2020, 9 , 1051. [CrossRef]

47. Samandari, N.; Mirza, A.H.; Kaur, S.; Hougaard, P.; Nielsen, L.B.; Fredheim, S.; Mortensen, H.B.; Pociot, F. Influence of Disease Duration on Circulating Levels of miRNAs in Children and Adolescents with New Onset Type 1 Diabetes. Noncoding RNA 2018, 4, 35. [CrossRef]

48. Özdirik, B.; Stueven, A.K.; Mohr, R.; Geisler, L.; Wree, A.; Knorr, J.; Demir, M.; Vucur, M.; Loosen, S.H.; Benz, F.; et al. Analysis of miR-29 Serum Levels in Patients with Neuroendocrine Tumors-Results from an Exploratory Study. J. Clin. Med. 2020, 9, 2881. [CrossRef]

49. Marttila, S.; Rovio, S.; Mishra, P.P.; Seppälä, I.; Lyytikäinen, L.P.; Juonala, M.; Waldenberger, M.; Oksala, N.; Ala-Korpela, M.; Harville, E.; et al. Adulthood blood levels of hsa-miR-29b-3p associate with preterm birth and adult metabolic and cognitive health. Sci. Rep. 2021, 11, 9203. [CrossRef] [PubMed]

50. Grabowski, K.; Herlan, L.; Witten, A.; Qadri, F.; Eisenreich, A.; Lindner, D.; Schädlich, M.; Schulz, A.; Subrova, J.; Mhatre, K.N.; et al. Cpxm2 as a novel candidate for cardiac hypertrophy and failure in hypertension. Hypertens. Res. 2021, 45, $292-307$. [CrossRef]

51. Dixon, D.M.; Choi, J.; El-Ghazali, A.; Park, S.Y.; Roos, K.P.; Jordan, M.C.; Fishbein, M.C.; Comai, L.; Reddy, S. Loss of muscleblindlike 1 results in cardiac pathology and persistence of embryonic splice isoforms. Sci. Rep. 2015, 5, 9042. [CrossRef]

52. Xue, K.; Wang, Y.; Hou, Y.; Wang, Y.; Zhong, T.; Li, L.; Zhang, H.; Wang, L. Molecular characterization and expression patterns of the actinin-associated LIM protein (ALP) subfamily genes in porcine skeletal muscle. Gene 2014, 539, 111-116. [CrossRef] [PubMed]

53. Lodder, E.M.; Scicluna, B.P.; Beekman, L.; Arends, D.; Moerland, P.D.; Tanck, M.W.; Adriaens, M.E.; Bezzina, C.R. Integrative genomic approach identifies multiple genes involved in cardiac collagen deposition. Circ. Cardiovasc. Genet. 2014, 7, 790-798. [CrossRef] [PubMed]

54. Kiedzierska, A.; Smietana, K.; Czepczynska, H.; Otlewski, J. Structural similarities and functional diversity of eukaryotic discoidin-like domains. Biochim. Biophys. 2007, 1774, 1069-1078. [CrossRef] [PubMed]

55. Schissel, S.L.; Dunsmore, S.E.; Liu, X.; Shine, R.W.; Perrella, M.A.; Layne, M.D. Aortic Carboxypeptidase-Like Protein Is Expressed in Fibrotic Human Lung and its Absence Protects against Bleomycin-Induced Lung Fibrosis. Am. J. Pathol. 2009, 174, 818-828. [CrossRef] [PubMed]

56. Eisenreich, A. Regulation of Vascular Function on Posttranscriptional Level. Thrombosis 2013, 2013, 3452. [CrossRef]

57. Chiang, M.H.; Liang, C.J.; Lin, L.C.; Yang, Y.F.; Huang, C.C.; Chen, Y.H.; Kao, H.L.; Chen, Y.C.; Ke, S.R.; Lee, C.W.; et al. miR-26a attenuates cardiac apoptosis and fibrosis by targeting ataxia-telangiectasia mutated in myocardial infarction. J. Cell. Physiol. 2020, 235, 6085-6102. [CrossRef] 
58. Huang, Y.; Tang, S.; Huang, C.; Chen, J.; Li, J.; Cai, A.; Feng, Y. Circulating miRNA29 family expression levels in patients with essential hypertension as potential markers for left ventricular hypertrophy. Clin. Exp. Hypertens. 2017, 39, 119-125. [CrossRef]

59. Panizo, S.; Carrillo-López, N.; Naves-Díaz, M.; Solache-Berrocal, G.; Martínez-Arias, L.; Rodrigues-Díez, R.R.; Fernández-Vázquez, A.; Martínez-Salgado, C.; Ruiz-Ortega, M.; Dusso, A.; et al. Regulation of miR-29b and miR-30c by vitamin D receptor activators contributes to attenuate uraemia-induced cardiac fibrosis. Nephrol. Dial. Transpl. 2017, 32, 1831-1840. [CrossRef]

60. Xiao, Y.; Zhang, X.; Fan, S.; Cui, G.; Shen, Z. MicroRNA-497 Inhibits Cardiac Hypertrophy by Targeting Sirt4. PLoS ONE 2016, 11, e0168078. [CrossRef]

61. Wan, X.; Chen, S.; Fang, Y.; Zuo, W.; Cui, J.; Xie, S. Mesenchymal stem cell-derived extracellular vesicles suppress the fibroblast proliferation by downregulating FZD6 expression in fibroblasts via micrRNA-29b-3p in idiopathic pulmonary fibrosis. J. Cell Physiol. 2020, 235, 8613-8625. [CrossRef]

62. Widlansky, M.E.; Jensen, D.M.; Wang, J.; Liu, Y.; Geurts, A.M.; Kriegel, A.J.; Liu, P.; Ying, R.; Zhang, G.; Casati, M.; et al. miR-29 contributes to normal endothelial function and can restore it in cardiometabolic disorders. EMBO Mol. Med. 2018, 10, e8046. [CrossRef] [PubMed]

63. Yamada, Y.; Takanashi, M.; Sudo, K.; Ueda, S.; Ohno, S.I.; Kuroda, M. Novel form of miR-29b suppresses bleomycin-induced pulmonary fibrosis. PLoS ONE 2017, 12, e0171957. [CrossRef] [PubMed]

64. Yang, F.; Li, P.; Li, H.; Shi, Q.; Li, S.; Zhao, L. microRNA-29b Mediates the Antifibrotic Effect of Tanshinone IIA in Postinfarct Cardiac Remodeling. J. Cardiovasc. Pharmacol. 2015, 65, 456-464. [CrossRef] [PubMed]

65. Zhang, Y.; Huang, X.R.; Wei, L.H.; Chung, A.C.; Yu, C.M.; Lan, H.Y. miR-29b as a therapeutic agent for angiotensin II-induced cardiac fibrosis by targeting TGF- $\beta /$ Smad3 signaling. Mol. Ther. 2014, 22, 974-985. [CrossRef] [PubMed]

66. Horita, M.; Farquharson, C.; Stephen, L.A. The role of miR-29 family in disease. J. Cell. Biochem. 2021, 122, 696-715. [CrossRef]

67. Saliminejad, K.; Khorram Khorshid, H.R.; Soleymani Fard, S.; Ghaffari, S.H. An overview of microRNAs: Biology, functions, therapeutics, and analysis methods. J. Cell. Physiol. 2019, 234, 5451-5465. [CrossRef] [PubMed]

68. Ban, E.; Jeong, S.; Park, M.; Kwon, H.; Park, J.; Song, E.J.; Kim, A. Accelerated wound healing in diabetic mice by miRNA-497 and its anti-inflammatory activity. Biomed. Pharmacother. 2020, 121, 109613. [CrossRef] [PubMed]

69. Zhang, X.; Liu, Y.; Han, Q. Puerarin Attenuates Cardiac Hypertrophy Partly Through Increasing Mir-15b/195 Expression and Suppressing Non-Canonical Transforming Growth Factor Beta (Tgf $\beta$ ) Signal Pathway. Med. Sci. Monit. 2016, 22, 1516-1523. [CrossRef]

70. Magaye, R.R.; Savira, F.; Hua, Y.; Xiong, X.; Huang, L.; Reid, C.; Flynn, B.L.; Kaye, D.; Liew, D.; Wang, B.H. Attenuating PI3K/Akt-mTOR pathway reduces dihydrosphingosine 1 phosphate mediated collagen synthesis and hypertrophy in primary cardiac cells. Int. J. Biochem. Cell Biol. 2021, 134, 105952. [CrossRef]

71. Livak, K.J.; Schmittgen, T.D. Analysis of relative gene expression data using real-time quantitative PCR and the 2(-Delta Delta C(T)) Method. Methods 2001, 25, 402-408. [CrossRef]

72. Eisenreich, A.; Langer, S.; Herlan, L.; Kreutz, R. Regulation of podoplanin expression bymicroRNA-29b associateswith its antiapoptotic effect in angiotensin II-induced injury of human podocytes. J. Hypertens. 2016, 34, 323-331. [CrossRef] [PubMed] 